\title{
Surviving the sauna
}

\section{LJ.F. (Jo) Hermans,}

Leiden University·The Netherlands·E-mail: Hermans@Physics.LeidenUniv.nl

$\mathrm{H}$ uman beings are not made for living in a $90^{\circ} \mathrm{C}$ environment. And yet this is the temperature in the average sauna. How do we cope with such harsh conditions?

First, we use a towel to sit on, or we touch wood. Touching metal at that temperature is no fun at all. Even the glass door feels hot, although its thermal conductivity is far below that of metals, and its temperature is only about $60^{\circ} \mathrm{C}$, halfway between in and outside temperature. Second, the air is dry, which enhances cooling by perspiration. Incidentally, the dry air comes for free: Due to the steepness of the water vapour pressure curve, even if the outside air at, say, 20 degrees is $100 \%$ humid, the humidity drops to $3 \%$ once the air is heated to $90^{\circ} \mathrm{C}$.If it freezes outside, that would even drov to $1 \%$, provided that no water is added.

How fast would our body heat up, if we neglect perspiration? Let's do a back-of-theenvelope calculation. First the conduction term. Since the effective air layer surrounding our body can be assumed to be around $3 \mathrm{~mm}$ thick, assuming a body surface area of $1.7 \mathrm{~m}^{2}$ and a temperature difference of $50 \mathrm{~K}$, we find some $700 \mathrm{~W}$. Likewise, the radiation term yields about $800 \mathrm{~W}$. So, conduction and radiation are roughly equally important, just like in normal circumstances. The difference is that they are reversed in the sauna. And they are an order of magnitude larger, due to the larger temperature difference and the fact that we have ..eh... adapted our clothing. So the total heat load on our body is $1,5 \mathrm{~kW}$, which corresponds to the power of an electric heater! Tall people suffer extra, in view of the vertical temperature gradient.

$38 \cdot$ volume $37 \cdot$ number 6
How fast will our body start to heat up? Taking a fair estimate for the heat capacity of our body of $200 \mathrm{~kJ} / \mathrm{K}$, we finda heating rate of $0.5 \mathrm{~K}$ per minute - as long as perspiration is negligible.

This is a sure way to disaster. So after a few minutes the sweating should begin. And it does, fortunately, even before we notice that our skin gets wet. Keeping up with the $1,5 \mathrm{~kW}$ heat load by sheer sweating would require 2.2 liter per hour. Our body will not be able to evaporate that much without forced air circulation.

Being physicists, we surely want to do a small experiment.Why not put some water on the stove, and see what happens? This makes us feel even hotter, and the question is why. Here is an educated guess. At least four contributions can be identified. First, the $100^{\circ} \mathrm{C}$ steam coming off the stove is somewhat hotter than the sauna air. Second, it causes forced convection, which will heat our body even more, particularly if our skin is still dry. Third, the humidity goes up, which makes perspiration more difficult. And fourth. the thermal conductivity of water vapour is slightly higher than that of dry air, since water molecules are a bit lighter (and therefore faster) than $\mathrm{N}_{2}$ or $\mathrm{O}_{2}$. Which of those contributions is the dominant one may be something to sort out next time we are in the sauna. After all, there is time enough to do some calculations and experiments.

But don't forget to keep an eye on the hourglass... . \%

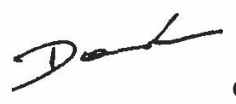

